\title{
Desarrollo de una prueba de ELISA para el diagnóstico de infección por Brucella canis en perros
}

\author{
María Ignacia Meza, Patricio Retamal, Consuelo Borie, Pedro Abalos \\ Departamento de Medicina Preventiva Animal, Universidad de Chile, Facultad de Ciencias Veterinarias y \\ Pecuarias. Santa Rosa 11.735, La Pintana. Casilla 2, correo 15, La Granja. Email: pabalos@uchile.cl
}

\begin{abstract}
Resumen
El diagnóstico definitivo y específico de la brucelosis en caninos causada por Brucella canis (B. canis) se realiza mediante el aislamiento de la bacteria desde muestras patológicas o sangre. Sin embargo, como la enfermedad se caracteriza por presentar periodos abacterémicos, un cultivo negativo no excluye la posibilidad de infección. La alternativa más ampliamente utilizada es la detección de anticuerpos frente a la infección y debido a que tanto $B$. ovis y $B$. canis comparten componentes antigénicos con la cepa vacuna Brucella abortus RB51 (B. abortus CRB51), ésta podría ser usada como antígeno en el diagnóstico serológico de la enfermedad. En el presente estudio, se describe un enzimoinmunoensayo indirecto (ELISAI) para el serodiagnóstico de brucelosis canina utilizando un extracto altamente purificado de lipopolisacárido rugoso (LPS-R) de Brucella abortus CRB51, cuyos resultados son comparados con la técnica contra inmunoelectroforesis (CIEF), que utiliza un antígeno extraído de una cepa de B. ovis, que contiene tanto proteínas como al LPS rugoso. El análisis de los resultados indicó asociación estadística entre ambas pruebas $(\mathrm{p}>0,05)$ para el diagnóstico de brucelosis canina. Además, ambas pruebas obtuvieron un alto índice de concordancia $(\mathrm{K}=0.961)$. Estos resultados hacen del ELISA-I propuesto una prueba promisoria al utilizar un antígeno más purificado y entregar resultados cuantitativos.
\end{abstract}

